\title{
Status of Strongyloidiasis in Japan, 2000-2017
}

\author{
Hiroshi Ikuno, ${ }^{1 *}$ Takashi Ishikawa, ${ }^{1}$ and Kazumi Norose ${ }^{2}$ \\ ${ }^{1}$ Department of Bacteriology, BML, Inc., Kawagoe, Japan; ${ }^{2}$ Department of Infection and Host Defense, Graduate School of Medicine, Chiba \\ University, Chiba, Japan
}

\begin{abstract}
We reported 865 cases of soil-transmitted nematodiasis occurring in Japan during 2000-2017. The predominant nematode was Strongyloides stercoralis ( $n=279,32.3 \%$ of all cases), and other species included Ascaris lumbricoides (30.7\%), Trichuris trichiura (23.1\%), and Ancylostomidae spp. (13.9\%). Strongyloides stercoralis was detected primarily in patients in Okinawa and Kagoshima prefectures, which are in the south of Japan and are endemic areas for this parasitic infection, and also in about half of the prefectures of all Japan. At least 15.5 cases of strongyloidiasis occurred on average each year. The period incidence rate of strongyloidiasis cases relative to the total population of Japan was 0.012 cases per $10^{5}$ person-years. The male-to-female ratio was 2.1 . The average age was $75.1 \pm 16.9$ years, and $96.1 \%$ of patients were older than 50 years. Several reasons may explain why this previously non-endemic outside of Okinawa region, serious nematode disease is now found in much of Japan, including the increased number of transmigration and sightseeing trips in Japan, use of immunosuppressive drugs, and lack of awareness of the risks. Thus, information of strongyloidiasis and its risks must be disseminated to travelers, residents, and physicians to prevent this life-threatening parasite infection.
\end{abstract}

\section{INTRODUCTION}

Strongyloidiasis, the chronic parasitic disease caused by Strongyloides stercoralis, is a soil-transmitted nematodiasis. It is particularly life-threatening in immunocompromised patients because of hyperinfection and dissemination of larvae (disseminated strongyloidiasis). ${ }^{1}$ Human infection is typically caused by contact with soil containing filariform larvae. The infection is likely to last for decades because of parthenogenesis and subsequent autoinfection. ${ }^{2}$ Infection may be acquired even by intake of drinking water contaminated with larvae. ${ }^{3}$ In addition, the possibility of infection from mammals to humans has long been debated. ${ }^{4}$

Approximately 30-100 million people worldwide are infected with S. stercoralis. ${ }^{5,6}$ In Asia, reports on the prevalence and/or incidence rates of strongyloidiasis from countries, such as China, ${ }^{7}$ Thailand, ${ }^{8,9}$ Taiwan, ${ }^{10}$ Lao PDR, ${ }^{11}$ and Australia, ${ }^{12}$ note that $S$. stercoralis infection should not be ignored. Some reports on the prevalence rate indicate that strongyloidiasis is endemic in the Okinawa prefecture in Japan. ${ }^{13-16}$ However, to the best of our knowledge, until now, there has been no report on the incidence of strongyloidiasis throughout Japan, despite it being the most likely to cause mortality, unlike other soil-transmitted helminth infections.

The Department of Bacteriology, BML Inc. (Kawagoe, Saitama, Japan), routinely identifies and diagnoses parasites when requested by domestic medical institutions. In the last 18 years from 2000 , we examined 279 cases of strongyloidiasis. In this article, we report the etiologic agents, geographical distribution, and incidence rate of strongyloidiasis in Japan.

\section{MATERIALS AND METHODS}

Fecal samples. Fecal samples from patients with persistent diarrhea and/or eosinophilia were sent to the Department of Bacteriology, BML Inc., by physicians from all over Japan for diagnosis of soil-transmitted helminths under temperature

*Address correspondence to Hiroshi Ikuno, Department of Bacteriology, BML, Inc., 1361-1, Kawagoe, Saitama, Japan. E-mail: h-ikuno@ bml.co.jp control $\left(1-15^{\circ} \mathrm{C}\right)$ and without fixation in formalin solution. The eggs and/or larvae in the fecal samples were identified by direct smear and concentration methods in 2000-2017. From 2012 , the agar plate culture method was added to the analysis. Identification of the larval species was carried out by morphology and morphometric markers, such as the length, width, ratio of the stomach and intestine, characteristic notches on the tail-end of the filariform larva, and reproductive organ shape in free-living adult males and females. ${ }^{17}$ Eggs were identified based on morphology and size only. Eggs and larvae were not identified by DNA analysis in this study. Hospital addresses were recorded from 2000, and those were assumed to be the patient residences because detailed information on patient past residences was unavailable. Patient characteristics, such as age and gender, were recorded from 2012.

Statistical analysis. The number of strongyloidiasis cases was computed by region and year to assess geographical and chronologic patterns. The results were plotted on maps for the entire study period and are reported as mean \pm SD. The incidence rates were calculated by dividing the number of strongyloidiasis (numerator) per year/period by the population at risk (denominator) during a period of time (personyears) multiplied by 100,000 and expressed as "cases per $10^{5}$ person-years." The population at risk was obtained from e-Stat, a government statistics portal site where Japanese statistics can be viewed. ${ }^{18}$

Ethics statement. The information obtained in this study was not used for any other purposes. Only aggregate data were examined. Clinical and epidemiological data were anonymized. No patient-identifiable personal information was used. This study was subject to ethics review in accordance with ethical rules in BML Inc. (permit number, 19-005) and at Chiba University (permit number, 3352).

\section{RESULTS}

Annual number of nematode species, including S. stercoralis. Approximately 1,714,000 fecal samples were sent from nationwide hospitals where patients were admitted during the study period. Of these samples, protozoans, nematodes, flukes, and tapeworms were found to be positive 
in 2,031 (0.11\%), 865 (0.05\%), 695 (0.04\%), and $370(0.02 \%)$ cases, respectively. Among 865 cases with nematodes, S. stercoralis accounted for most (279 cases, $32.3 \%)$, followed by Ascaris lumbricoides (266 cases, 30.7\%), Trichuris trichiura (200 cases, 23.1\%), and Ancylostomidae spp. (120 cases, $13.9 \%)$. At least 15.5 strongyloidiasis cases were estimated to occur per year in Japan. The number of nematodeinfected cases has tended to gradually decrease year by year (Figure 1). Although the number of cases infected with A. lumbricoides and Ancylostomidae spp. has been decreasing, cases with $S$. stercoralis have remained fairly constant. Japanese accounted for $89.6 \%$ (250 cases) of cases, foreigners accounted for $7.9 \%$ (22 cases), and $2.5 \%$ ( 7 cases) were unknown. There was no case in which only eggs of S. stercoralis were detected in the fecal samples. Eggs and rhabditiform larvae were always found at the same time (Figure 2). In addition, adult free-living males and females (Figure 2D and E) were often observed on agar plate cultures.

Geographical distribution of strongyloidiasis. We analyzed these 279 strongyloidiasis cases, according to the addresses of the hospitals for each year. During the survey period, the regions where strongyloidiasis occurred most often were Okinawa prefecture (182 cases, $65.2 \%$ ), followed by Kagoshima prefecture (20 cases, 7.2\%), Tokyo (20 cases, $7.2 \%$ ), and others (57 cases, $27.6 \%$ ) (Figure 3). Strongyloidiasis occurred widely (24/47 prefectures) throughout Japan from Hokkaido to Okinawa prefectures (Figure 4A), although the number of infected patients was higher in the southern regions than that in the northern regions.

The period incidence rate of strongyloidiasis cases relative to the total population of Japan was 0.012 cases per $10^{5}$ person-years. Geographical patterns of the incidence rates for each prefecture are shown in Figure 4B. The highest incidence rates were observed in Okinawa $\left(0.70\right.$ cases per $10^{5}$ person-year) and Kagoshima (0.068 cases per $10^{5}$ personyear) prefectures. In Tokyo, the number of strongyloidiasis cases was the same as that in Kagoshima prefecture, but the incidence rate ranked ninth ( 0.008 cases per $10^{5}$ person-year). Thus, the frequencies of enterocolitis with $S$. stercoralis in Okinawa and Kagoshima prefectures were 87 and 8 times greater, respectively, than those in Tokyo.

In Okinawa prefecture, strongyloidiasis patients were observed most frequently on Okinawajima Island, which belongs to the Okinawa Islands, especially in Okinawa-shi and Nagoshi, the central parts of Okinawajima Island, and Tomigusukushi, Urasoe-shi, Itoman-shi, and Haebaru-cho, the southern parts of Okinawajima Island (Figure 5A). Patients were also found more frequently on Miyakojima, Irabujima, and Ishigakijima islands, which belong to the Sakishima Islands and are located further south of Okinawa prefecture. The period incidence rates of strongyloidiasis cases relative to the total population of each region and island are shown in Figure 5B. The highest incidence rate was 5.32 on Irabujima Island, followed by the Miyakojima, Okinawajima, and Ishigakijima islands. The incidence rate of Irabujima Island was 8.0 times higher than that of Okinawajima Island. In Okinawajima Island, the highest incidence rate was 2.41 in Okinawa-shi, followed by Nago-shi, Tomigusuku-shi, and Haebaru-cho.

In Kagoshima prefecture, on the Amami Islands (especially Oshima, Kikaishima, Yoronjima, and Tokunoshima islands) located at the Kagoshima-Okinawa border, strongyloidiasis was found widely (Figure $5 \mathrm{C}$ ). Yoronjima Island recorded the highest incidence rate ( 1.00 cases per $10^{5}$ person-year). It was 33.3 times higher than Kagoshima-shi in far north (Figure 5D). Apparently, higher levels of infection have occurred on the islands in the southern part of this prefecture.

The ratio of the Japanese to foreign patients was roughly 9:1 (i.e., Japanese 250 cases, foreigners 22 cases, and unknown
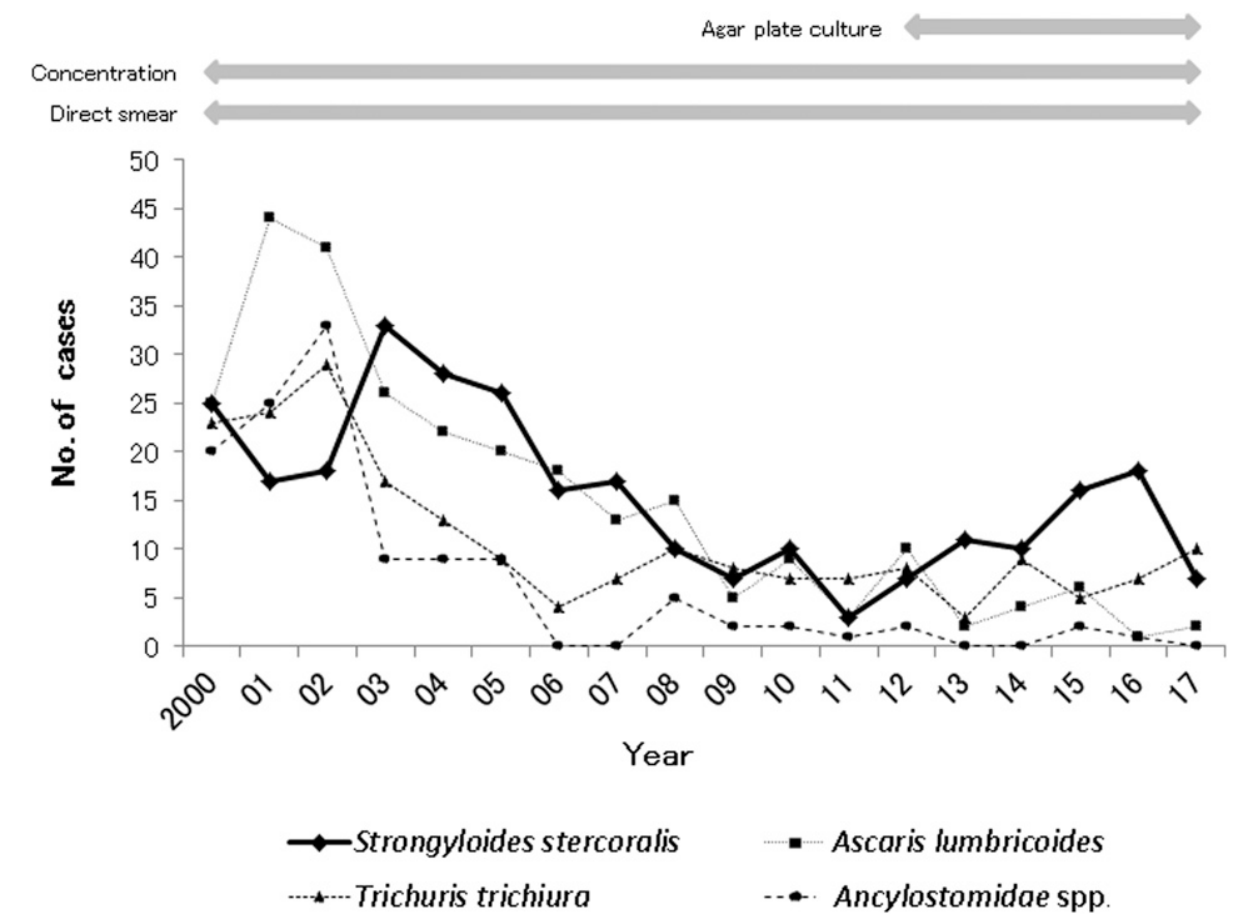

FIGURE 1. Annual number of nematode species identified in patient fecal samples in Japan, 2000-2017. 


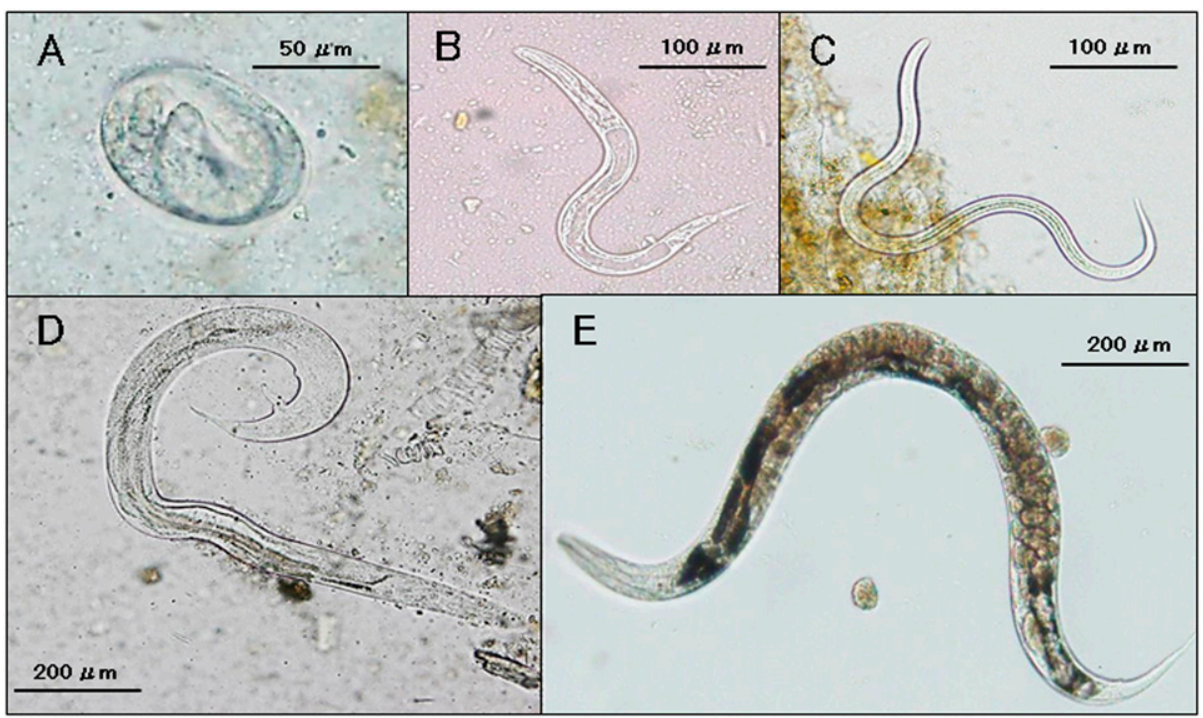

FIGURE 2. Various growth patterns of Strongyloides stercoralis observed in patient feces by a microscope. (A) Embryonated egg, $80 \mu \mathrm{m} \times 40 \mu \mathrm{m}$. (B) Rhabditiform larvae, $300 \mu \mathrm{m} \times 18 \mu \mathrm{m}$. (C) Filariform larvae, $500 \mu \mathrm{m} \times 15 \mu \mathrm{m}$. (D) Adult male of free-living stage, $1 \mathrm{~mm} \times 50 \mu \mathrm{m}$. (E) Adult female of free-living stage, $1.2 \mathrm{~mm} \times 70 \mu \mathrm{m}$. This figure appears in color at www.ajtmh.org.

seven cases). The average annual number of visitors to Japan from abroad during the study period (18 years) was approximately 10.1 million people. ${ }^{19}$ Thus, the incidence rate of foreigners infected with strongyloidiasis was 0.012 cases per $10^{5}$ person-year.

Gender and age analyses of patients. Gender was recorded for 62 of 69 patients who participated from 2012 to 2017: 42 males $(60.8 \%), 20$ females (28.9\%), and seven unknown cases (10.3\%) (Figure 6A). There were 2.1 times more male than female patients. Age was recorded for 52 of 69 patients: ages ranged from 19 to $>90$ years, and the mean age $( \pm S D)$ of patients was 75.1 years $( \pm 16.9)$ (Figure 6B). Most patients (of either gender) were older than 50 years (96.1\%), and patients aged 80-89 years accounted for the largest number of cases. The median age was 76.5 years (male: 75.0 ; female: 80.5 years). At age 50 and more, males predominated in all age-groups.

Notably, a 19-year-old Japanese man (who lives in Fukui prefecture located in middle part of Japan and facing the Sea of Japan) and a 34-year-old Japanese woman (who lives in Saitama prefecture located near Tokyo) were confirmed to have strongyloidiasis, but other information, such as their

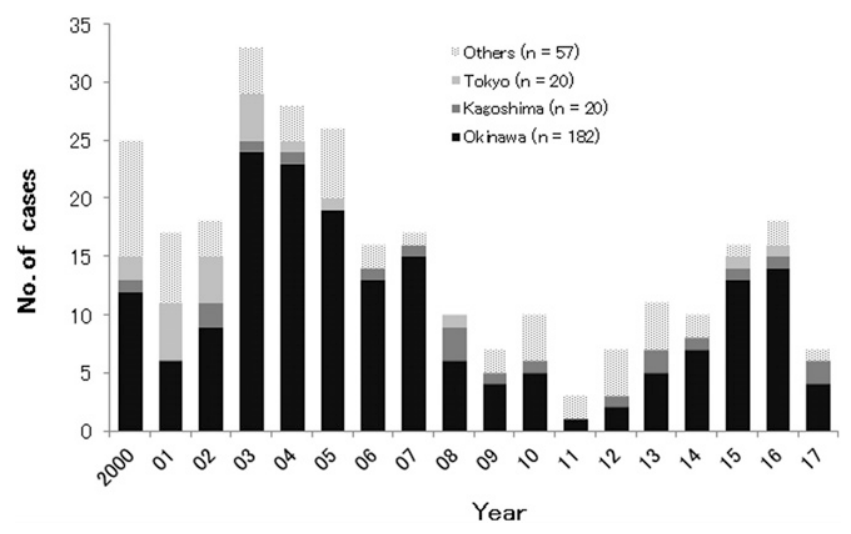

Figure 3. Annual number of strongyloidiasis in Japan, 2000-2017. travel histories abroad and/or to the Okinawa and Kagoshima prefectures, is unknown (Figure 4A).

\section{DISCUSSION}

Soil-transmitted helminths have infected approximately 1.5 billion people worldwide in the warm and humid environments of tropical, subtropical, and temperate regions. ${ }^{20}$ In Japan, the occurrence of soil-transmitted helminthiasis declined sharply since its peak in 1949 because of group therapies after mass screening and the development of social infrastructures. ${ }^{21}$ In addition, "Japan Agricultural Standards," revised in 2000, prohibits the use of human feces as a fertilizer in principle because human feces might facilitate the transmission of soil-transmitted helminthiasis. ${ }^{22}$ Despite these effective preventative measures by the government, infections with S. stercoralis have still been reported in the Okinawa and Kagoshima prefectures. ${ }^{23-25}$ Okinawa has a high infection rate of human T-cell lymphotropic virus type 1 (HTLV-1), a virus associated with adult T-cell leukemia/lymphoma, and a close relationship between $S$. stercoralis and HTLV-1 infections has been reported. ${ }^{26}$ Human T-cell lymphotropic virus type 1 is an important cofactor in accelerated autoinfection which causes severe form of strongyloidiasis. ${ }^{26}$

Our hospital-based study showed that at least 15.5 strongyloidiasis cases occur per year in Japan and are widely distributed in almost half of the prefectures of Japan. The actual rate is probably much higher because $S$. stercoralis is also detected by other facilities and hospitals.

Our hospital-based study revealed, for the first time, that the period incidence rate of strongyloidiasis cases relative to the total population of Japan was 0.012 cases per $10^{5}$ personyears, and the incidence rate among foreigners was the same. Infected foreigners had no effect on the incidence rate in Japan in our study. However, as the number of foreigner-visitors from endemic countries is increasing because of globalization, we need to keep a close watch for the re-emergence of strongyloidiasis in Japan. In Spain, the period incidence rate 


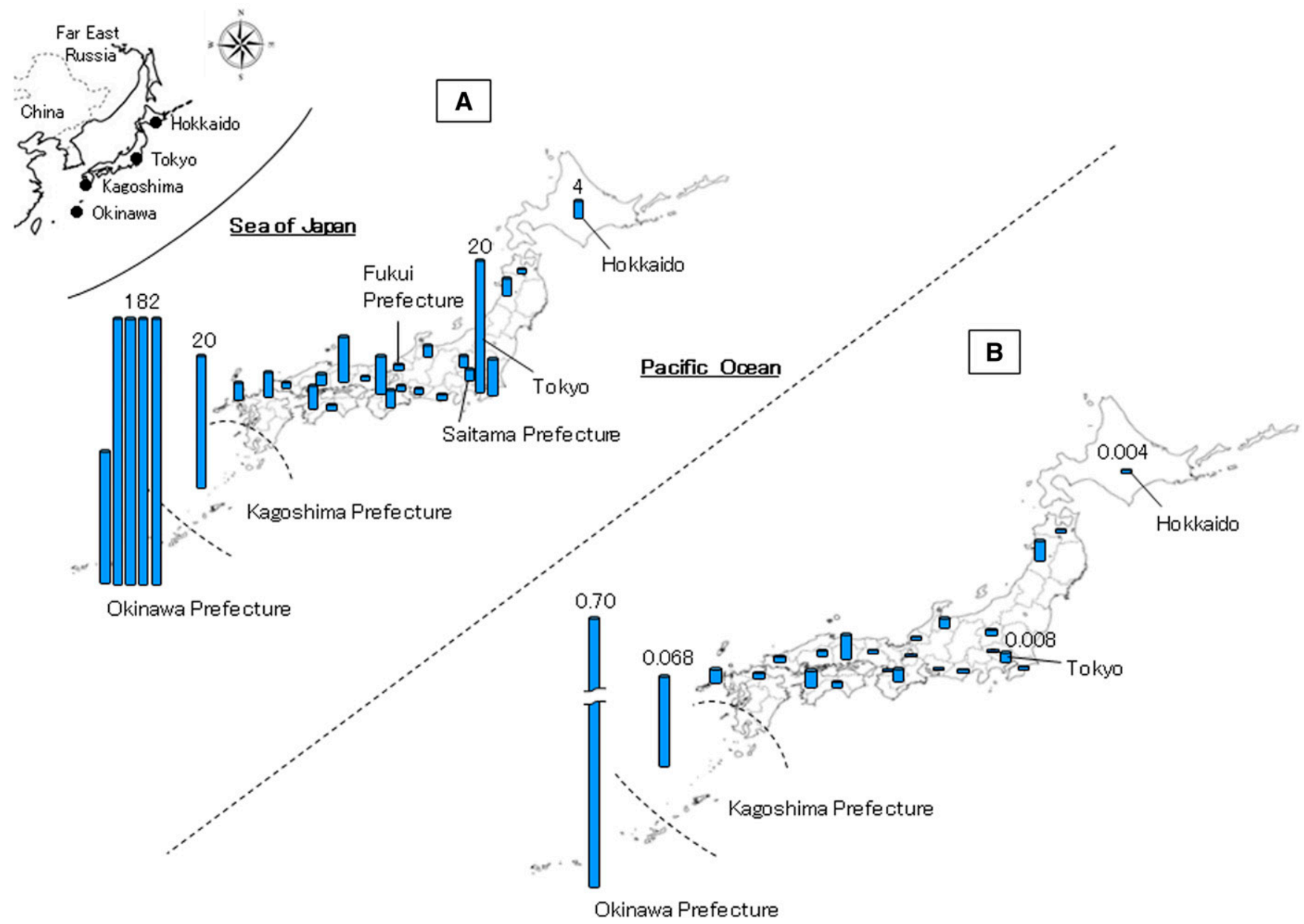

FIGURE 4. Cumulative cases and incidence of strongyloidiasis in Japan, 2000-2017. (A) Geographical distribution. One case was unknown and was, therefore, not included. Inset shows the location of Japan in East Asia. (B) Incidence per $10^{5}$ person-years by administrative district in Japan, 2000-2017. This figure appears in color at www.ajtmh.org.

of strongyloidiasis cases admitted to hospitals was 0.06 cases per $10^{5}$ person-years and that of foreign-born people would be much more ( 0.85 cases per $10^{5}$ person-years), and most of the cases were immigrants or travelers. ${ }^{27}$ It might be because the number of immigrants from endemic areas, such as North Africa and Latin America, has been rapidly increasing in Spain. ${ }^{28}$

From the viewpoint of public health, based on our study, patients infected with $S$. stercoralis were found not only in Okinawa and Kagoshima prefectures but also in northern Japan, including Hokkaido, which is far from endemic areas. We speculate that $S$. stercoralis was found widely in Japan for several reasons. 1) The number of people traveling to and from endemic areas is increasing for tourism and commercial purposes. In 2017, the number of visitors to Okinawa prefecture was roughly 10 million, and it increased by $9.2 \%$ last year. ${ }^{29} 2$ ) Hosts of $S$. stercoralis are primates, including humans and dogs. ${ }^{30,31}$ Furthermore, S. stercoralis from humans has infected cats experimentally. ${ }^{32}$ 3) $S$. stercoralis can adhere to the fresh leafy vegetables that are sold at markets of Okinawajima Island (M. Sato, personal communication). The infection was transmitted in an experimental setting even by drinking water contaminated with larvae ${ }^{3}$ and so, this pathogenic parasite could infect humans through the mucous membrane of the mouth and/or esophagus when humans eat contaminated fresh vegetables or drink contaminated water. ${ }^{33-35}$ Contaminated fresh vegetables from markets might increase the risk of the disease to the local consumers and producers. The distribution system for food is highly developed in Japan, and people in prefectures far from Okinawa prefecture might be infected. 4) In Japan, highly advanced medical treatments, such as immunosuppressive drugs, are sometimes used for patients who might be infected with this parasite without recognizing the risk of reactivation of this infection.

Although strongyloidiasis has attracted attention in endemic areas such as the Okinawa and Kagoshima prefectures in Japan, information about $S$. stercoralis is insufficient in the non-endemic regions because the national epidemiological situation of this parasite is not well understood. This knowledge gap between non-endemic and endemic regions can be a very dangerous situation for strongyloidiasis patients and medical staff. In hospitals with little recognition of this pathogen, the infection could be life-threatening to patients if the appropriate therapies are delayed.

In past studies, the prevalence of $S$. stercoralis infection in Okinawa prefecture was estimated to be $5.2-9.6 \%{ }^{15,26}$ Asato et al. reported a prevalence of $S$. stercoralis infection in 
A

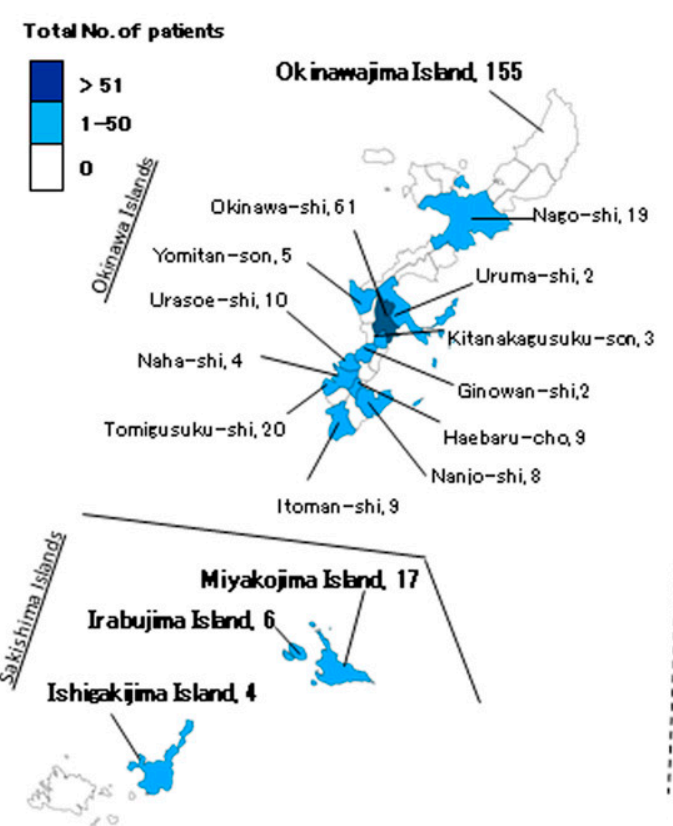

B

No. of patients per

10 person-year

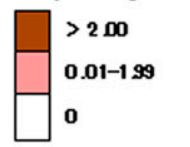

Okinamajma Is and $\mathbf{0 . 6 6}$

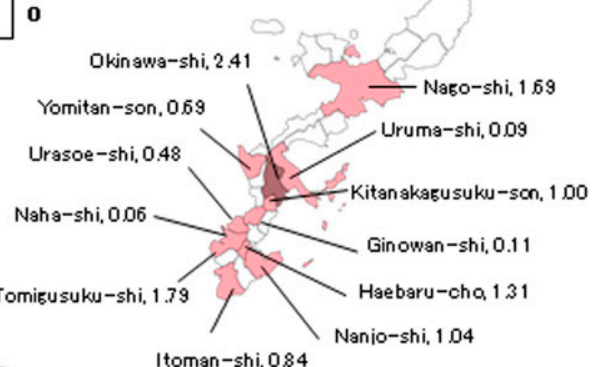

Itoman-shi, 084

Miyakojma kstand 1.84

Irabujima ksland $\mathbf{5 . 3 2}$

Ishigakijima kland, 0.45
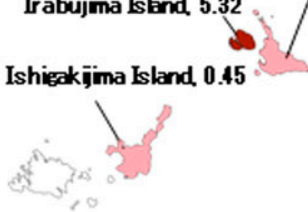

C

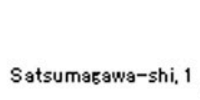

Satsumasawa-shi,

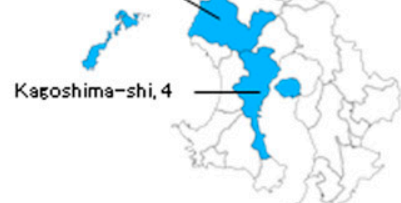

Taneeashima Island 2

Yakushima Kland 2

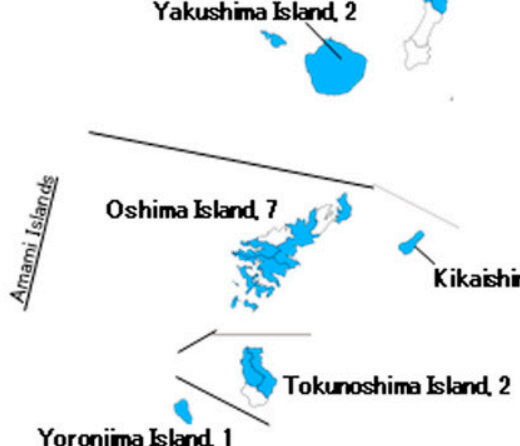

4

Yoronjima Eland 1
Okinawa Prefecture
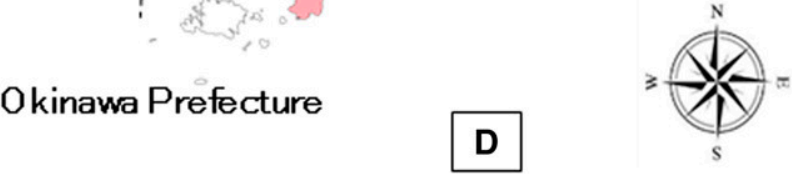

Satsumasawa-shi, 0.05
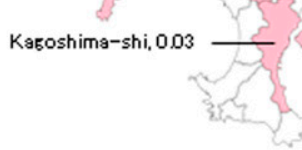

Yakushima Kland, 0.91

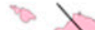

Taneeashima Eland $\mathbf{0 . 3 1}$
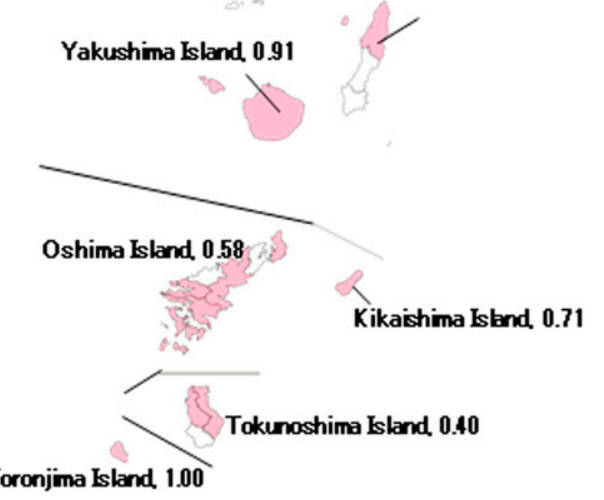

\section{Kagoshima Prefecture}

FIGURE 5. Cumulative cases and incidence of strongyloidiasis at Okinawa and Kagoshima prefectures in Japan, 2000-2017. (A) Geographical distribution at Okinawa prefecture. Hospital addresses of three patients were unknown. (B) Incidence per $10^{5}$ person-years at Okinawa prefecture. (C) Geographical distribution at Kagoshima prefecture. (D) Incidence per $10^{5}$ person-years at Kagoshima prefecture.

Okinawajima Island and showed that the southern part of the island was highly infected but the middle part was much less infected. ${ }^{14}$ However, in our study, many strongyloidiasis patients were observed in the southern part of Okinawajima
Island, including Naha-shi, and in the middle part, including Okinawa-shi, the most populous city, and Nago-shi. As Okinawa-shi and Nago-shi have regional core hospitals, the number of strongyloidiasis cases might be even greater. The 

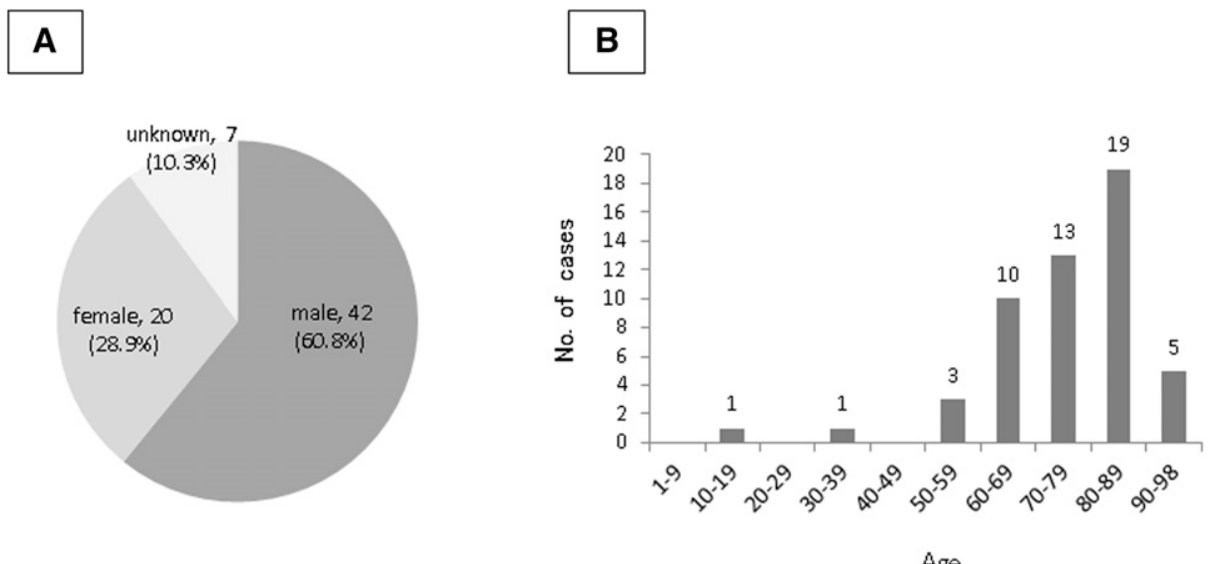

FIGURE 6. (A) Gender of patients with strongyloidiasis in Japan, 2012-2017. (B) Age distribution of patients with strongyloidiasis in Japan, 2012-2017.

differences in the data may result from differences in the analytical methods. Furthermore, our study on the incidence rate showed that the southern islands, rather than Okinawajima Island, are at high risk of S. stercoralis infection caused by hygiene and lifestyle.

There have been no reports about the prevalence and incidence rates of strongyloidiasis in Kagoshima prefecture until now. Our data on the incidence rates showed that strongyloidiasis in Kagoshima prefecture was frequently observed in the Amami Islands near Okinawa prefecture. Although which area in Kagoshima prefecture is the northern limit of the endemic regions is unclear, this study strongly suggests that the Amami Islands are endemic areas. As for the remaining issues, whether S. stercoralis occurs autochthonously in Yakushima and Tanegashima islands, which are located north of the Amami Islands, needs further research.

The number of male patients was almost two times greater than that of females in our study. In the incidence rate study of other countries, male-to-female patient ratios were reported to be 2.19 and 1.8 in China $^{7}$ and Spain, ${ }^{27}$ respectively. In a prevalence study, males were reported to be more infected than females. ${ }^{15}$ The reasons of this gender difference include frequent opportunities for the infection in male lifestyle, more susceptibility to the infection, and significant resistance to treatment. $^{15}$

Age was also a factor. Patients older than 50 years accounted for $96.1 \%$, and the largest age-group was 80-89 years in this study. Thus, in Japan, ongoing transmission is likely rare. Given that autoinfection occurs in strongyloidiasis, the few remaining chronic patients who have come for medical attention might reflect the number of cases of strongyloidiasis per year and the period incidence rate relative to the total population of Japan. In China, $69 \%$ of the patients were aged $>41$ years, and those aged $41-50$ years accounted for the largest number of cases. ${ }^{7}$ In Spain, $30.4 \%$ of the patients were aged $>50$ years, and the highest number of cases was observed in the 30-39 age-group. ${ }^{27}$ In the past reports about the prevalence study in Okinawa prefecture, patients older than 50 years accounted for more than $95 \%$ of total patients. ${ }^{15}$ In the immunocompetent individual, chronic strongyloidiasis is usually asymptomatic, as human immunity limits the number of parasites in the intestine. By contrast, as people older than 50 years have lower immunity than younger people and the percentage of hyperinfection increases, larvae are detected easily and the incidence rate may become high.

In Okinawa prefecture, a previous age-related prevalence study reported that $S$. stercoralis infections were not surveyed in patients born after the $1960 \mathrm{~s},{ }^{13}$ under the assumption that new infections would not occur in Okinawa prefecture in the present day. ${ }^{15,16,26}$ Nevertheless, our study showed one Japanese patient with strongyloidiasis was aged less than 20 years. Considering that $S$. stercoralis has established a unique survival strategy, such as remarkable persistence in the human body due to the parthenogenetic autoinfection cycle and low-intensity chronic infections, this parasite may have avoided eradication somewhere in the subtropical and warm regions in Japan. Therefore, not only the elderly individuals but also younger people could be infected with this parasite.

In this study, we detected S. stercoralis by microscopic examination of stool samples, which is a relatively insensitive method. In cases of hyperinfection, larvae are relatively easily seen in feces with a microscope. However, in cases of lowlevel infection, it is difficult to detect larvae from feces of immunocompetent patients. Therefore, negative results might be obtained even with an agar plate culture method that is more sensitive than other fecal examination methods. ${ }^{36}$ Thus, to confirm $S$. stercoralis infection more sensitively, widely available serological assays and/or molecular diagnosis, such as polymerase chain reaction methods, ${ }^{37}$ are desirable in the future.

The main limitation of this study is that information on the residence, occupation, and travel of the patients is uncertain. To improve the reliability of the study, detailed patient information from the hospitals should be obtained in the future.

In Japan, strongyloidiasis has been a neglected parasitic infection in prefectures other than the endemic area of infestation. However, this study revealed that S. stercoralis infection is a public health concern even in Japan. Most of the population of Japan is unaware of the risk for strongyloidiasis associated with infective larvae. Thus, information regarding parasitic infection and warnings of the risks associated with these infections must be disseminated to people with a suspected infection, medical staff, and physicians even in non-endemic areas. Requena-Méndez et al. ${ }^{38}$ proposed guidelines for screening and management of strongyloidiasis in non-endemic countries. Optimally, an appropriate strategy 
for controlling this disease would be developed after acquiring more accurate epidemiological, prevalence, and incidence data.

\section{CONCLUSION}

Here, we report for the first time on the incidence rate of strongyloidiasis in Japan. When administering immunosuppressive agents to elderly individuals who have lived or traveled to Okinawa prefecture and/or Amami Islands, physicians should take adequate steps to prevent and treat hyperinfection syndrome and disseminated strongyloidiasis. In addition, even in non-endemic areas, physicians should keep in mind that they might encounter symptomatic patients with strongyloidiasis because of increasing migration and globalization.

Received December 29, 2019. Accepted for publication May 18, 2020.

Published online June 22, 2020.

Acknowledgments: We thank the staff members of the domestic medical institutions who participated in the survey and would like to thank Gary Howard for critical reading of the manuscript.

Disclosure: H. I. and T. I. are employees of BML.

Authors' addresses: Hiroshi lkuno and Takashi Ishikawa, Department of Bacteriology, BML, Inc., Kawagoe, Japan, E-mails: h-ikuno@ bml.co.jp and takashi_ishikawa@bml.co.jp. Kazumi Norose, Department of Infection and Host Defense, Graduate School of Medicine, Chiba University, Chiba, Japan, E-mail: norose@faculty.chiba-u.jp.

\section{REFERENCES}

1. Nutman TB, 2017. Human infection with Strongyloides stercoralis and other related Strongyloides species. Parasitology 144: 263-273.

2. Grove DI, 1989. Strongyloidiasis: A MajorRoundworm Infection of Man. Philadelphia, PA: Taylor \& Francis.

3. Grove DI, 1996. Human strongyloidiasis. Adv Parasitol 38: 251-309.

4. Jaleta TG, Zhou S, Bemm FM, SchärF, Khieu V, Muth S, Odermatt $\mathrm{P}$, Lok JB, Streit A, 2017. Different but overlapping populations of Strongyloides stercoralis in dogs and humans-dogs as a possible source for zoonotic strongyloidiasis. PLoS Negl Trop Dis 9: e0005752.

5. Olsen $A$, van Lieshout $L$, Marti $H$, Polderman $T$, Polman $K$, Steinmann P, Stothard R, Thybo S, Verweij JJ, Magnussen P, 2009. Strongyloidiasis - the most neglected of the neglected tropical diseases? Trans R Soc Trop Med Hyg 103: 967-972.

6. Bisoffi $Z$ et al., 2013. Strongyloides stercoralis: a plea for action. PLoS Negl Trop Dis 9: e2214.

7. Wang C, Xu J, Zhou X, Li J, Yan G, James AA, Chen X, 2013. Strongyloidiasis: an emerging infectious disease in China. Am J Trop Med Hyg 88: 420-425.

8. Prasongdee TK, Laoraksawong P, Kanarkard W, Kraiklang R, Sathapornworachai K, Naonongwai S, Laummaunwai P, Sanpool O, Intapan PM, Maleewong W, 2017. An eleven-year retrospective hospital-based study of epidemiological data regarding human strongyloidiasis in northeast Thailand. BMC Infect Dis 17: 627.

9. Laoraksawong $\mathrm{P}$, Sanpool $\mathrm{O}$, Rodpai $\mathrm{R}$, Thanchomnang $\mathrm{T}$, Kanarkard W, Maleewong W, Kraiklang R, Intapan PM, 2018. Current high prevalences of Strongyloides stercoralis and Opisthorchis viverrini infections in rural communities in northeast Thailand and associated risk factors. BMC Public Health 31: 940.

10. Wu TC, Lei WY, Chen MC, Hu CT, 2012. Strongyloides stercoralis infection: a health issue regarding indigenous people in Taiwan. Trans $R$ Soc Trop Med Hyg 106: 468-472.

11. Senephansiri $P$, Laummaunwai $P$, Laymanivong $S$, Boonmar $T$, 2017. Status and risk factors of Strongyloides stercoralis infection in rural communities of Xayaburi Province, Lao PDR. Korean J Parasitol 55: 569-573.

12. Beknazarova M, Whiley H, Judd JA, Shield J, Page W, Miller A, Whittaker M, Ross K. 2018. Argument for inclusion of strongyloidiasis in the Australian national notifiable disease list. Trop Med Infect Dis 5: E61.

13. Arakaki T, Iwanaga M, Asato R, Ikeshiro T, 1992. Age-related prevalence of Strongyloides stercoralis infection in Okinawa, Japan. Trop Geogr Med 44: 299-303.

14. Asato R, Nakasone T, Yoshida C, Arakaki T, Ikashiro T, Murakami $\mathrm{H}$, Sakiyama H, 1992. Current status of Strongyloides infection in Okinawa, Japan. Jpn J Trop Med Hyg 20: 169-173.

15. Kobayashi J, Sato Y, Toma H, Shimabukuro I, Tasaki T, Takara M, Shiroma Y, 2000. Epidemiological features of Strongyloides infection in Okinawa, Japan: comparative study with other endemic areas. Jpn J Trop Med Hyg 28: 9-14.

16. Hirata $\mathrm{T}$, Nakamura $\mathrm{H}$, Kinjo N, Hokama A, Kinjo F, Yamane N, Fujita J, 2007. Prevalence of Blastocystis hominis and Strongyloides stercoralis infection in Okinawa, Japan. Parasitol Res 101: 1717-1719.

17. Neva FA, 1994. Intestinal nematodes of human beings. Neva FA, ed. Basic Clinical Parasitology. Norwalk, CT: Appleton \& Lange, 123-128.

18. Statistics Bureau of Japan, 2017. Preliminary Counts of Population of Japan. Available at: http://www.stat.go.jp/data/jinsui/ index.htm. Accessed August 15, 2019.

19. JNTO, 2017. Japan Tourism Statistics. Available at: https:// statistics.jnto.go.jp/graph/\#category--5. Accessed August 20, 2019.

20. WHO, 2016. Summary of global update on preventive chemotherapy implementation in 2015. Wkly Epidemiol Rec 91: 456-459.

21. Kobayashi A, Hara T, Kajima J, 2006. Historical aspects for the control of soil-transmitted helminthiases. Parasitol Int 55: S289-S291.

22. JAS, 2000. Japanese Agricultural Standard. Available at: http:// www.maff.go.jp/e/policies/standard/jas/index.html. Accessed August 15, 2019.

23. Setoyama M, Fukumaru S, Takasaki T, Yoshida H, Kanzaki T, 1997. SLE with death from acute massive pulmonary hemorrhage caused by disseminated strongyloidiasis. Scand $J$ Rheumatol 26: 389-391.

24. Miyazaki $M$ et al., 2010. Minimal change nephrotic syndrome in a patient with strongyloidiasis. Clin Exp Nephrol 14: 367-371.

25. Ikeuchi $\mathrm{N}$ et al., 2016. Strongyloides stercoralis infection causing obstructive jaundice and refractory pancreatitis: a lesson learned from a case study. Intern Med 55: 2081-2086.

26. Tanaka T, Hirata T, Parrott G, Higashiarakawa M, Kinjo T, Kinjo T, Hokama A, Fujita J, 2016. Relationship among Strongyloides stercoralis infection, human T-Cell lymphotropic virus type 1 infection, and cancer: a 24-year cohort inpatient study in Okinawa, Japan. Am J Trop Med Hyg 94: 365-370.

27. Belhassen-García M, Alonso-Sardón M, Martinez-Perez A, Soler C, Carranza-Rodriguez C, Pérez-Arellano JL, Muro A, Salvador $F, 2017$. Soil-transmitted helminths study group of the SEMTSI. Surveillance of strongyloidiasis in Spanish in-patients (1998-2014). PLoS One 28: e0189449.

28. Barra A, Contucci P, Sandell R, Vernia C, 2014. An analysis of a large dataset on immigrant integration in Spain. The statistical mechanics perspective on social action. Sci Rep 4: 4174.

29. Okinawa Prefecture, 2018. Tourist Statistics Overview. Available at: http://www.pref.okinawa.jp/site/bunka-sports/kankoseisaku/ 14734.html. Accessed August 15, 2019.

30. Schad GA, Hellman ME, Muncey DW, 1984. Strongyloides stercoralis: hyperinfection in immunosuppressed dogs. Exp Parasitol 57: 287-296.

31. Hasegawa H, Kalousova B, McLennan MR, Modry D, ProfousovaPsenkova I, Shutt-Phillips KA, Todd A, Huffman MA, Petrzelkova $\mathrm{KJ}, 2016$. Strongyloides infections of humans and great apes in Dzanga-Sangha protected areas, central African republic and in degraded forest fragments in Bulindi, Uganda. Parasitol Int 65: 367-370.

32. Kostopoulou D, Claerebout E, Arvanitis D, Ligda P, Voutzourakis N, Casaert S, Sotiraki S, 2017. Abundance, zoonotic potential and risk factors of intestinal parasitism amongst dog and 
cat populations: the scenario of Crete, Greece. Parasit Vectors 25: 43.

33. Zeehaida M, Zairi NZ, Rahmah N, Maimunah A, Madihah B, 2011. Strongyloides stercoralis in common vegetables and herbs in Kota Bharu, Kelantan, Malaysia. Trop Biomed 28: 188-193.

34. Eraky MA, Rashed SM, Nasr Mel S, El-Hamshary AM, Salah El-Ghannam A, 2014. Parasitic contamination of commonly consumed fresh leafy vegetables in Benha, Egypt. $J$ Parasitol Res 2014: 613960.

35. Punsawad C, Phasuk N, Thongtup K, Nagavirochana S, Viriyavejakul P, 2019. Prevalence of parasitic contamination of raw vegetables in Nakhon Si Thammarat province, southern Thailand. BMC Public Health 19: 34.
36. Arakaki T, Iwanaga M, Kinjo F, Saito A, Asato R, Ikeshiro T, 1990. Efficacy of agar-plate culture in detection of Strongyloides stercoralis infection. J Parasitol 76: 425-428.

37. Buonfrate $D$, Requena-Mendez A, Angheben A, Cinquini $M$, Cruciani M, Fittipaldo A, Giorli G, Gobbi F, Piubelli C, Bisoffi Z, 2018. Accuracy of molecular biology techniques for the diagnosis of Strongyloides stercoralis infection-A systematic review and meta-analysis. PLoS Negl Trop Dis. 9: e0006229.

38. Requena-Méndez A, Buonfrate $D$, Gomez-Junyent J, Zammarchi L, Bisoffi Z, Muñoz J, 2017. Evidence-based guidelines for screening and management of strongyloidiasis in non-endemic countries. Am J Trop Med Hyg 97: 645-652. 